NBER WORKING PAPER SERIES

\title{
DECOMPOSING MEDICAL-CARE EXPENDITURE GROWTH
}

\author{
Abe Dunn \\ Eli B. Liebman \\ Adam Shapiro \\ Working Paper 23117 \\ http://www.nber.org/papers/w23117 \\ NATIONAL BUREAU OF ECONOMIC RESEARCH \\ 1050 Massachusetts Avenue \\ Cambridge, MA 02138 \\ February 2017
}

We would like to thank Ana Aizcorbe, Ernie Berndt, Michael Chernew, David Cutler, Bill Marder, Joe Newhouse, Allison Rosen, and Jack Triplett. We would also like to thank the participants at the NBER/CRIW Conference on Measuring and Modeling Health Care Costs and 2013 iHEA 9th World Congress. The views expressed in this paper are solely those of the authors and do not necessarily reflect the views of the Bureau of Economic Analysis, the Federal Reserve Bank of San Francisco, the Board of Governors of the Federal Reserve System or the National Bureau of Economic Research.

NBER working papers are circulated for discussion and comment purposes. They have not been peer-reviewed or been subject to the review by the NBER Board of Directors that accompanies official NBER publications.

(C) 2017 by Abe Dunn, Eli B. Liebman, and Adam Shapiro. All rights reserved. Short sections of text, not to exceed two paragraphs, may be quoted without explicit permission provided that full credit, including (C) notice, is given to the source. 
Decomposing Medical-Care Expenditure Growth

Abe Dunn, Eli B. Liebman, and Adam Shapiro

NBER Working Paper No. 23117

February 2017

JEL No. I10,I11

\section{ABSTRACT}

Medical-care expenditures have been rising rapidly, accounting for over 17 percent of GDP in 2012. In this study, we assess the sources of the rising medical-care expenditures in the commercial sector. We employ a novel framework for decomposing expenditure growth into four components at the disease level: service price growth, service utilization growth, treated disease prevalence growth, and demographic shift. The decomposition shows that growth in prices and treated prevalence are the primary drivers of medical-care expenditure growth over the 2003 to 2007 period. There was no growth in service utilization at the aggregate level over this period. Price and utilization growth were especially large for the treatment of malignant neoplasms. For many conditions, treated prevalence has shifted towards preventive treatment and away from treatment for late-stage illnesses.

Abe Dunn

Bureau of Economic Analysis

Abe.Dunn@bea.gov

Eli B. Liebman

Department of Economics

Duke University

Durham, NC 27708

ebs30@duke.edu
Adam Shapiro

Federal Reserve Bank of San Francisco

adam.shapiro@sf.frb.org 


\title{
Decomposing Medical-Care Expenditure Growth*
}

\author{
Abe Dunn, Eli Liebman, and Adam Hale Shapiro
}

February 1, 2017

\begin{abstract}
Medical-care expenditures have been rising rapidly, accounting for over 17 percent of GDP in 2012. In this study, we assess the sources of the rising medical-care expenditures in the commercial sector. We employ a novel framework for decomposing expenditure growth into four components at the disease level: service price growth, service utilization growth, treated disease prevalence growth, and demographic shift. The decomposition shows that growth in prices and treated prevalence are the primary drivers of medical-care expenditure growth over the 2003 to 2007 period. There was no growth in service utilization at the aggregate level over this period. Price and utilization growth were especially large for the treatment of malignant neoplasms. For many conditions, treated prevalence has shifted towards preventive treatment and away from treatment for late-stage illnesses.
\end{abstract}

\section{Introduction}

Medical-care expenditures per capita in the United States is larger and rising faster relative to other developed countries (see Chernew and Newhouse (2012) and Chandra

*We would like to thank Ana Aizcorbe, Ernie Berndt, Michael Chernew, David Cutler, Bill Marder, Joe Newhouse, Allison Rosen, and Jack Triplett. We would also like to thank the participants at the NBER/CRIW Conference on Measuring and Modeling Health Care Costs and 2013 iHEA 9th World Congress. The views expressed in this paper are solely those of the authors and do not necessarily reflect the views of the Bureau of Economic Analysis, the Federal Reserve Bank of San Francisco, or the Board of Governors of the Federal Reserve System. 
and Skinner (2012)). In 2012, health care accounted for more than 17 percent of U.S. GDP, which was nearly double the average of other OECD countries. Despite the substantial expenditures on medical care in the United States, many gaps remain in our understanding of the sources of expenditure growth. Current national statistics that track spending by service category (for example, physicians, hospitals and prescription drugs) do not convey information about spending for specific disease categories. To fill this void, academics and policy makers have advocated for more detailed statistics on health-care expenditures centered around a key target of health spending: disease treatment (see Berndt et al. (2000) and Accounting for Health and Health Care (2010)). Additional information on disease spending may provide greater insight into how to contain and efficiently manage health-care expenditure growth.

We analyze health-care expenditures in the commercial sector over the period 2003 to 2007. The commercial health-care market is economically important, accounting for 60 percent more expenditures than Medicare in 2012. Over this period of study, commercial medical-care expenditures per commercially insured person grew by 26 percent, surpassing the 20 percent growth in nominal GDP per capita. ${ }^{1}$ Prior research studies have examined several factors driving the growth in medical-care expenditures, but each of these studies leaves out pieces of the puzzle. For instance, Roehrig and Rousseau (2011), Starr, Dominiak, and Aizcorbe (2013) and Thorpe, Florence, and Joski (2004) look at the cost of disease and the prevalence of disease, but do not analyze changes in service prices or service utilization (that is, the quantity of services per episode of care); Aizcorbe and Nestoriak (2011) and Dunn, Liebman, Pack, and Shapiro (2012) look at cost of disease treatment used as a measure of disease price growth, but do not assess disease prevalence. Statistical agencies such as the Bureau of Labor Statistics (BLS) and Bureau of Economic Analysis (BEA), as well as research by Bundorf, Royalty, and Baker (2009) report changes in service prices for precisely defined services, but do not focus on the cost of disease treatment or disease prevalence. None of the prior literature has analyzed all these factors in one setting, which can leave policymakers without context

\footnotetext{
${ }^{1}$ Commercial medical-care expenditure growth is calculated from the National Health Expenditure Accounts. Overall inflation as reported by the BEA PCE deflator grew by 11.5 percent over the period of study. Commercial premiums also grew faster than inflation with a growth rate of around 32 percent according to estimates from the Kaiser Employee Health Benefit Survey.
} 
for the different results and without understanding about where these studies disagree. This is important, since we find that broad generalizations for why spending changes often overlook important trends that are disease-specific.

The aim of this study is to more comprehensively assess the sources of medical-care expenditure growth. We do so by decomposing expenditure growth into four distinct components: service-price growth, service-utilization growth, prevalence-of-treated-disease growth, and demographic shift. We track and dissect these key components of medicalcare expenditure growth for the years 2003 to 2007 for the commercial sector using a rich claims database from MarketScan that contains millions of enrollees. The framework presented in this paper breaks expenditures into various components applying a similar methodology to that developed in Dunn, Shapiro and Liebman (2014). First, using demographic population weights assessed in Dunn, Liebman, and Shapiro (2014a), we extract expenditure growth attributable to demographic shifts - primarily, an aging population. Second, as advocated by most health experts, we allocate expenditures into disease-level categories. This allows protocols, technologies, and prices relevant for treating specific diseases to vary uniquely over time. Third, we break expenditures down into expenditures per treatment and treated prevalence of a disease. For example, in the case of hypertension, we track the number of episodes of treatment for hypertension per capita as well as the expenditures per episode of treating hypertension. Finally, expenditures per episode of treatment is split into service price and service utilization. Service price represents the payment for a specific service, for example, a 15-minute office visit. Service utilization represents the quantity, or intensity, of services performed during an episode of treatment. For example, in our methodology, a 30-minute doctor office visit will be a higher quantity of services than a 15-minute office visit.

Analyzing each of these factors within a single framework allows for a simple and tractable way of comparing the various contributors to medical-care expenditure growth. Foremost, determining whether expenditures are rising from disease prevalence, service utilization, service prices, or demographic reasons is informative to policy makers attempting to hold back the rising cost of health care. The methodology also provides a more precise mapping between BLS methods (which track price per service) and the types of price indexes that health economists have advocated (expenditures per episode 
for a specific disease, often referred to as a disease price).

We find that, between 2003 and 2007, rising medical-care expenditures per capita (that is, per commercially enrolled person) came from two primary sources: an increase in the prevalence of treated diseases (accounting for around one-third of the increase in expenditure growth) and an increase in service prices (accounting for around half of the increase in expenditure growth). The remaining increase is attributable to demographic shifts, in particular, a slightly aging commercially insured population. Interestingly, there is no aggregate growth in expenditures due to service utilization per episode. In fact, service utilization may be falling slightly for some conditions and increasing for others. While service price growth is a large contributor to expenditure growth, it is important to highlight that price growth does not greatly exceed inflation. After deflating price growth measures by the national personal consumption expenditure (PCE) deflator, we find that growth in prevalence accounts for 60 percent of expenditure growth in our sample. Around 27 percent is attributable to real service price growth and 18 percent to demographic shift. Service utilization has no impact on growth.

The three largest contributors to expenditure growth are the medical practice categories of orthopedics, gastroenterology, and endocrinology. These practice categories represented 33 percent of expenditures in 2003 but made up 40 percent of expenditure growth between 2003 and 2007. Each of these practice categories had large growth in service prices and the prevalence of treated disease. The major practice category with the largest expenditure growth was preventive and administrative services, which grew 64 percent over the sample period, although this category accounted for only 2.4 percent of spending in 2003. On the flip side, cardiology made up 12 percent of 2003 expenditures but accounted for less than 8 percent of the share in expenditure growth. This relatively slow rise in expenditures per capita for cardiology services is attributable to a decline in the prevalence of heart disease but also to a decrease in service utilization. Our decomposition for the cardiology condition category shows that the decline in service utilization was driven by a shift from inpatient to outpatient services and from brand to generic drugs. These shifts may be indicative of greater efficiency, since fewer resources are necessary to treat each episode. The shifts are reflected in lower disease price growth relative to the service price index, which holds utilization constant. This finding is con- 
sistent with the work of Cutler et al. (1998), who find that a price index that allows for greater substitution across services leads to lower price growth for the case of heart attack treatments.

Digging deeper into the specific disease categories reveals some interesting patterns. Within cardiology and endocrinology services, there has been a large increase in the prevalence of early-stage contributors to heart disease such as hypertension, diabetes, obesity, and hyperlipidemia. However, there has been a decline in the prevalence of ischemic heart disease. This pattern may indicate that people are simply seeking treatment for heart disease at an earlier stage of illness. Indeed, there has been a large increase in spending on preventive services across the entire sample. For example, two of the largest contributors to growth in spending for gastroenterology were attributable to preventive services. Specifically, there was a 41 percent increase in expenditures per capita on "gastroenterology signs and symptoms" (a large portion of which includes colonoscopy) and a 34 percent increase in expenditures per capita for patients with "non-malignant neoplasm of intestines" (e.g., benign polyps). Our decomposition shows that the majority of this growth is attributable to an increase in the prevalence of treatment and demographic shifts.

Our decomposition also sheds light on the factors that contribute to the rapid rise in the treatment cost of cancer. Over the five-year sample period, expenditures per capita rose twice as fast for malignant neoplasms (48 percent growth in expenditures per capita) than non-malignant neoplasms (24 percent growth in expenditures per capita). A large reason for the discrepancy is the difference in growth in the costs of treatment (that is, expenditures per episode of care). Service prices for malignant neoplasms grew over twice as fast as service prices for non-malignant neoplasms. This may indicate that more expensive and innovative services are playing a role in cancer spending growth.

This paper finds results in the aggregate that are consistent with Bundorf, Royalty, and Baker (2009) that use a similar data and time period. Specifically, after accounting for overall inflation, they show that the growth in the health sector is mostly driven by nonprice factors. Our paper adds to their findings by providing a more nuanced picture of the factors leading to more health care utilization and higher prices. In particular, we find that overall utilization growth is rising because of a higher treated prevalence growth 
for many conditions, while for other condition categories, such as cardiology, it appears that demographics play a more important role. We also find that service prices do not rise uniformly and that price growth for the treatment of malignant neoplasms is growing

particularly fast. Several other disease-specific findings are highlighted throughout the text.

One limitation of our study is that it looks at a shorter time period and only a subset of the population (i.e., the commercial population) compared to some of the previous studies that apply survey data, such as Roehrig and Rousseau (2011), and Starr, Dominiak, and Aizcorbe (2013), so a direct comparison with our paper is not possible. Indeed, the use of large claims data is especially important for accurately measuring factors driving expenditure growth for precisely defined disease categories, to account for underreporting in survey data, and to study patterns in relatively rare but economically important health conditions (see Zuvekas and Olin (2009) and Aizcorbe et al. (2012)).

This paper focuses on the economic analysis of the components of medical care expenditure growth and trends. However, there are several methodological issues that arise when studying the components of expenditure growth that are not covered in this paper. Some of these topics are explored in companion pieces to this work: (1) Dunn, Liebman, Rittmueller and Shapiro (2014) examine different approaches for assigning medical services to disease categories and the effect of these assignments on the components of spending growth; (2) Dunn, Liebman, and Shapiro (2014b) examine alternative strategies for separating utilization and price, which offer some implications for medical-care price indexes; (3) Dunn, Liebman, and Shapiro (2014a) examine the representativeness of the data used in our study and the effects of analyzing different samples and applying alternative weights; and (4) Dunn, Shapiro, and Liebman (2014) study the geographic differences in expenditure levels across MSAs.

\section{Methodology of Index Construction}

The methodology of this paper borrows heavily from the Dunn, Shapiro, and Liebman (2014) study of geographic variation in disease expenditures. However, instead of 
focusing on differences across regions, we examine differences over time. To begin, we measure expenditures per capita for disease $d$ for time period $t, C_{d, t}^{*}$ which is simply total expenditures for disease $d$ in period $t$ divided by the total commercial-insured population in period $t$. To create a measure of medical-care expenditure growth, we form the following expenditure-per-capita index $(E C I)$ :

$$
E C I_{d, t}=\frac{C_{d, t}^{*}}{C_{d, 0}^{*}},
$$

where $C_{d, 0}^{*}$ is expenditures per capita for disease $d$ in the base period, 0 . Next, we create a demographically fixed $E C I$, or $D E C I$, by applying age, geographic location, and gender weights to our selected commercially insured population, so that the age and sex distribution is identical across regions and time periods. ${ }^{2}$ A measure of demographically fixed medical care expenditure growth from period 0 (the base period) to $t$ is then:

$$
D E C I_{d, t}=\frac{C_{d, t}}{C_{d, 0}}
$$

where $C_{d, t}$ is expenditures per capita after fixing the demographic distribution to the base period. Note that any difference between the ECI and DECI will be attributable to demographic shifts in the commercially insured population. We label this the "demographic residual" (Dem):

$$
D e m_{d, t}=E C I_{d, t}-D E C I_{d, t}+1 .
$$

Since the denominator of the $C_{d, t}$ term is the full population, this measure of expenditure growth does not take into account the health of the population. For instance, if expenditures per capita are higher in the second period because more individuals develop ischemic heart disease (i.e., a rise in the prevalence of ischemic heart disease), the

\footnotetext{
${ }^{2}$ Age, sex and major census region counts of those with private health insurance were accessed for each year from http://www.census.gov/cps/data/cpstablecreator.html. The age categories were: 0 (babies only), 1-17, 18-24, 25-34, 35-44, 45-54, 55-64. This left us with 42 buckets ( 7 age buckets x 2 gender buckets $\mathrm{x} 4$ regions). Then, using those counts we weighted up the number of enrollees in each of those 42 buckets to match the population counts from the CPS. For the ECI, we weighted to the CPS population for each year, to compute the DECI we weight each year of our sample to the 2007 CPS population (see Dunn, Liebman, and Shapiro (2014a)).
} 
expenditure measure $C_{d, t}$ will grow, even if the expenditures per episode of heart disease does not change. Alternatively, $C_{d, t}$ may grow if the expenditures per heart disease episode increases, even if prevalence remains unchanged. In the following section we will decompose the growth in population expenditures into the prevalence of the condition and the expenditures per episode of the condition.

\subsection{Decomposing Expenditure Per Capita into Expenditure Per Episode and Prevalence of Treated Disease}

We divide demographically fixed expenditures per capita, $C_{d, t}$, into two components. One component is the prevalence of treated disease index, $P R E V_{d, t}$, which we define as growth in the demographically fixed prevalence of treated disease, $\operatorname{prev}_{d, t}$ :

$$
\operatorname{PREV} V_{d, t}=\frac{\operatorname{prev}_{d, t}}{\operatorname{prev}_{d, 0}}
$$

where $\operatorname{prev}_{d, t}$ is the number of episodes treated in the population divided by the commercially insured population, holding fixed the demographic distribution. Note that prev $v_{d, t}$ includes only those who are aware of their condition and seek some medical attention, and excludes those individuals who are unaware of their condition or are aware of their condition and choose not to be treated. ${ }^{3}$ Note that the definition of treated prevalence in this paper denotes the number of episodes per capita rather than the number individuals treated per capita within a year, which is a measure that is often reported in the literature. ${ }^{4}$ However, work by Dunn, Liebman, Rittmueller, and Shapiro (2014) finds little differences in the treated prevalence growth or growth in cost per case when using

\footnotetext{
${ }^{3}$ Those individuals who have a condition but are unaware that they have a condition or do not seek medical attention for their condition would be considered in measuring the population's prevalence, but are not included in the treated prevalence figure.

${ }^{4}$ For cases of conditions that appear multiple times in a year, episodes of care per population is likely a more accurate measure of the probability that the disease is treated in the population. For example, comparing a population where the flu appears twice a year per person, to a population where the flu appears a single time per year, the episode-based statistic will reflect the higher probability of observing the flu in the first population. In practice, Dunn, Liebman, Rittmueller, and Shapiro (2014) find this difference to be unimportant when measuring changes in treated prevalence or cost per case.
} 
this alternative definition of treated prevalence and cost per case.

The second component of $C_{d, t}$ is the expenditures per episode $d, c_{d, t}$. This is sometimes referred to as cost per case or treatment cost in the literature. The value $c_{d, t}$ may be calculated by dividing total expenditures of disease $d$ by the number of episodes of disease $d$ in period $t$, holding fixed the demographic distribution to the base period. It follows that the medical-care expenditure index, or MCE index, is a measure of the medical-care expenditures for the treatment of an episode of care for a certain disease, and is defined as the dollar amount of medical care used until treatment is completed. ${ }^{5}$ Denoting $c_{d, 0}$ as the average expenditures per episode in the base period, $t=0$, the MCE index for disease $d$ is the ratio of the two measures:

$$
M C E_{d, t}=\frac{c_{d, t}}{c_{d, 0}}
$$

Since this index controls for the health of the individual, it may be viewed as measuring the cost of treatment. Thus, if the $M C E_{d, t}$ is larger than one, it signifies that the expenditure for treating disease $d$ is larger than the base period and if the index is less than one it signifies that the expenditure is less than the base.

Using these equations it follows that $C_{d, t}=c_{d, t} \cdot$ prev $_{d, t}$. From this we can see that the $D E C I_{d, t}$ may be decomposed into its two components, which include the episode-based index, $M C E_{d, t}$ and the prevalence of treated disease index, $P R E V_{d, t}: 6$

$$
D E C I_{d, t}=M C E_{d, t}+P R E V_{d, t}+\frac{\left(\operatorname{prev}_{d, t}-\operatorname{prev}_{d, 0}\right)\left(c_{d, t}-c_{d, 0}\right)}{\operatorname{prev}_{d, 0} c_{d, 0}}-1 .
$$

This equation makes it clear that the $D E C I$ will rise if there is either an increase in the $P R E V_{d, t}$ or an increase in the $M C E_{d, t}$. These two components of expenditure capture distinct elements of cost growth. Changes in the prevalence of a condition capture the changing health of the population, such as the growth in diabetes due to obesity. It may also reflect a growing awareness of a condition, such as the increase in awareness

\footnotetext{
${ }^{5}$ For example, for an individual with a broken foot, the episode of treatment will be defined by the dollars of medical services used to treat that condition from the first visit to a provider until the foot is healed. For medical conditions that are chronic, we interpret an episode as expenditure for services used to treat the chronic condition over a one-year period.

${ }^{6} \mathrm{~A}$ decomposition using $\operatorname{logs}$ is: $\log \left(D E C I_{d, t}\right)=\log \left(M C E_{d, t}\right)+\log \left(P R E V_{d, t}\right)$.
} 
and diagnosis of high cholesterol. The second component of care may be viewed as the price for treating the disease, which includes the prices of those services and also the mix of those services provided. Assuming that the quality of the underlying treatment mix remains constant, this treatment price reflects the productivity in the health sector for the treatment of disease $d$.

The indexes presented here are directly related to a simple and often reported figure, total medical-care expenditures per capita. To see this, we can create aggregate diseasespecific indexes from the population-based measure, $E C I_{d, t}$. When $E C I_{d, t}$ is weighted by the national expenditure share for each disease in the base period, this becomes a measure of medical-care expenditures per capita relative to the base period's medical-care expenditures per capita:

$$
\begin{aligned}
& E C I_{t}=\sum_{D} E C I_{d, t} \cdot\left(\text { Expenditure Share }_{0}\right) \\
& =\sum_{D} \frac{C_{d, t}}{C_{d, 0}} \cdot\left(\frac{C_{d, 0}}{\sum_{D} C_{d, 0}}\right)=\frac{\sum_{D} C_{d, t}}{\sum_{D} C_{d, 0}} \\
& =\frac{\text { Medical-Care Expenditures Per Person }}{t} \text {. }
\end{aligned}
$$

\subsection{Expenditure Per Episode Decomposition: Service Price and Service Utilization}

\subsubsection{A Motivating Example}

To help motivate our methodology for decomposing service price and service utilization, we start with a simple example. Consider a time period $t$ where people are treated for hypertension $(h)$ (i.e., high blood pressure) where there exists only one type of treatment available- a 15-minute office visit. Let 


$$
\begin{aligned}
N_{h, t} & =\text { Number of treated hypertension episodes. } \\
c_{h, t} & =\text { Average expenditure for hypertension per episode. }{ }^{7} \\
q_{h, t} & =\text { Number of } 15 \text {-minute office visits per episode. } \\
p_{h, t} & =\text { Price per } 15 \text {-minute office visit (i.e., } \frac{c_{h, t}}{q_{h, t}} .
\end{aligned}
$$

Also suppose there is a comparison or base time period, $t=0$, where the price for a 15-minute office visit for hypertension is $p_{h, 0}$. In this simple case, the relative price level of $t$ to 0 is simply $\frac{p_{h, t}}{p_{h, 0}}$. Clearly, this ratio reflects only differences in the contracted prices, not the number of 15-minute office visits. Similarly, the relative utilization level is $\frac{q_{h, t}}{q_{h, 0}}$ which depends only on the number of 15-minute office visits performed per episode. It follows that the relative expenditures per episode between $t$ and 0 may be expressed as:

$$
M C E_{h, t}=\frac{c_{h, t}}{c_{h, 0}}=\left(\frac{p_{h, t} \cdot q_{h, 0}}{p_{h, 0} \cdot q_{h, 0}}\right) \cdot\left(\frac{p_{h, t} \cdot q_{h, t}}{p_{h, t} \cdot q_{h, 0}}\right) .
$$

The first term in (7) is a price index, and the second term is a utilization index. Expanding on this example, now suppose that hypertension may be treated with two types of services, prescription drugs and physician office services, where the service categories correspond to the subscripts $(D)$ and $(O)$. That is, $q_{h, t, O}$ and $p_{h, t, O}$ are the utilization and price for the physician office visits, and $q_{h, t, D}$ and $p_{h, t, D}$ are the utilization and price for prescription drugs. Continuing with the index decomposition that is parallel to (7), but with two services, the decomposition becomes:

$$
\begin{aligned}
\frac{c_{h, t}}{c_{h, 0}} & =\frac{p_{h, t, O} \cdot q_{h, t, O}+p_{h, t, D} \cdot q_{h, t, D}}{p_{h, 0, O} \cdot q_{h, 0, O}+p_{h, 0, D} \cdot q_{h, 0, D}} \\
& =\left(\frac{p_{h, t, O} \cdot q_{h, 0, O}+p_{h, t, D} \cdot q_{h, 0, D}}{p_{h, 0, O} \cdot q_{h, 0, O}+p_{h, 0, D} \cdot q_{h, 0, D}}\right) \cdot\left(\frac{p_{h, t, O} \cdot q_{h, t, O}+p_{h, t, D} \cdot q_{h, t, D}}{p_{h, t, O} \cdot q_{h, 0, O}+p_{h, t, D} \cdot q_{h, 0, D}}\right)
\end{aligned}
$$

Again the first term corresponds to the price index and the second term corresponds to the utilization index. 


\subsubsection{The General Case}

In the general case, we define the medical-care expenditure for the treatment of an episode of a disease (that is, a specific condition) as the total dollar amount of medical care used until treatment is completed, including all service categories. ${ }^{8}$ To demonstrate how to decompose the $M C E$ in the general case, it is useful to start by showing that the average expenditure is calculated by totaling dollars spent on all services to treat the condition and dividing those dollars by the number of episodes: $c_{d, t}=\sum_{s} p_{d, t, s} Q_{d, t, s} / N_{d, t}$, where $Q_{d, t, s}$ is the quantity of services for service type, $s ; p_{d, t, s}$, is the service price for service type $s$; and $N_{d, t}$ is the number of episodes treated. To simplify, let $q_{d, t}$ be a vector of services utilized for the typical treatment of diseases at time $t, q_{d, t}=Q_{d, t} / N_{d, t}$, where the component of the utilization vector for service type $s$ is, $q_{d, t, s}=Q_{d, t, s} / N_{d, t}$. Similarly, let $p_{d, r t}$ be a vector of service prices, where the price for a particular service type and disease can be calculated by dividing its average expenditure by the average quantity of services provided: $p_{d, t, s}=\frac{c_{d, t, s}}{q_{d, t, s}}$ where $c_{d, t, s}$ is the average episode expenditure for disease $d$ for service type $s$ at time $t$. This decomposition allows us to create a service price and service utilization index. The service price index (SPI) is then calculated as

$$
S P I_{d, t}=\frac{p_{d, t} \cdot q_{d, 0}}{c_{d, 0}}
$$

which holds the utilization of services fixed at a base-period level. The SPI measures the compensation necessary to purchase a fixed utilization of medical goods when going from the base period to time $t$. The service utilization index (SUI) may be defined as:

$$
S U I_{d, t}=\frac{p_{d, 0} \cdot q_{d, t}}{c_{d, 0}}
$$

which holds the price of services fixed while allowing the utilization of services to vary. The SUI measures the compensation necessary to purchase medical goods in the time period $t$ to the amount of compensation necessary in the base period. We choose to apply Laspeyres indexes for price and quantity, so that the estimates may be compared to a base period: essentially answering the question, how much are disease expenditures

\footnotetext{
${ }^{8}$ For medical diseases that are chronic, we interpret an episode as the total expenditure for services used to treat the chronic disease over a one-year period.
} 
different than the base period due to price differences or due to utilization differences? With these indexes the decomposition that relates these three indexes is additive, rather than multiplicative. ${ }^{9}$ The relationship between these three indexes is described by the following decomposition:

$$
M C E_{d, t}=S P I_{d, t}+S U I_{d, t}+\frac{\left(q_{d, t}-q_{d, 0}\right)\left(p_{d, t}-p_{d, 0}\right)}{c_{d, 0}}-\frac{p_{d, 0} \cdot q_{d, 0}}{c_{d, 0}}
$$

Here the MCE index is equal to the service price index, $S P I_{d, t}$, plus the service utilization index, $S U I_{d, t}$, plus a cross term, $\frac{\left(q_{d, t}-q_{d, 0}\right)\left(p_{d, t}-p_{d, 0}\right)}{c_{d, 0}}$, and subtracting $\frac{p_{d, 0} \cdot q_{d, 0}}{c_{d, 0}}$ (which is close to 1 ). The cross term accounts for joint changes in both price vectors and utilization vectors and, in practice, the term is near zero. In the case where there are very few changes in utilization over time, $S U I_{d, t}$ is fixed near 1, then the $M C E_{d, t}$ will entirely be determined by service prices. Similarly, if there are very few changes in service prices over time, $S P I_{d, t}$, is near 1 , and the $M C E_{d, t}$ will entirely be determined by utilization.

\section{Data}

We use retrospective claims data for a sample of commercially insured patients from the MarketScan ${ }^{\circledR}$ Research Databases from Truven Health. The specific claims data used is the Commercial Claims and Encounters Database which contains data from the employer and health plan sources containing medical and drug data for several million commercially insured individuals, including employees, their spouses, and dependents. Each observation in the data corresponds to a line item in an "explanation of benefits" form in a medical claim. Each claim can consist of many records, and each encounter can consist of many claims.

We use a sample of enrollees that are not in capitated plans from the MarketScan database for the years 2003 to 2007 . We also limit our sample to enrollees with drug benefits because drug purchases will not be observed for individuals without drug cov-

\footnotetext{
${ }^{9}$ This approach follows others in the health literature that also apply additive decompositions (e.g., Roehrig and Rousseau (2011)), which leaves a cross-term. As another possibility, we could have used a Laspeyres index for the price index and a Paasche index for the quantity index, which provides an exact decomposition (e.g., SUI $\left.I^{\text {Laspeyres }} \cdot S P I^{\text {Paasche }}=M C E\right)$.
} 
erage. The MarketScan database tracks claims from all providers using a nationwide convenience sample of enrollees. Each enrollee has a unique identifier and includes age, sex, and region information that may be used when calculating patient weights. All claims have been paid and adjudicated. ${ }^{10}$

The claims data were processed using the Symmetry grouper from Optum. The grouper assigns each claim to a particular episode treatment group (ETG) disease and severity category. Thus each disease category $d$ represents a type of disease (e.g., hypertension), as well as the severity of the disease classified into up to four severity bins. A higher severity number indicates a more serious medical condition. In this manner, "hypertension 3" is a distinct disease with a higher severity relative to "hypertension 1."

The grouper uses a proprietary algorithm, based on clinical knowledge, that is applied to the claims data to assign each record to a clinically homogeneous episode. The episode grouper allocates all spending from individual claim records to a distinct condition; the grouper also uses other information on the claim (e.g., procedures) and information from the patient's history to allocate the spending. For instance, for claims submitted by a physician, the grouper uses the ICD-9 code to allocate spending. If there are procedure codes present, they can be used to decide which ICD-9 code is most applicable to that claim.

An advantage of using the grouper is that it can use patients' medical history to assign diseases to drug claims, which typically do not provide a diagnosis. For example, each claim is grouped to one distinct episode which consists of one disease grouping (ETG). The grouper works in chronological fashion, but can update old episodes as it gathers more information, so an early diagnosis of chest pain can be updated to heart disease as further ICD-9 codes arrive. This is in contrast to the primary diagnosis method which would imply that a person had both chest pain and heart disease. Furthermore, severity operates the same way: when someone is grouped to hypertension 3, their previous claims, which were grouped to hypertension 2 , get updated to hypertension 3.

Another advantage of the grouper over the primary diagnosis method is that it uses a patient's history to assign diseases to drug claims, which typically do not provide a diagnosis and account for a lot of spending. For instance, the grouper examines which

\footnotetext{
${ }^{10}$ Additional details about the data and the grouper used in this paper are in Dunn et al. (2012a).
} 
episodes the patient has, then matches their drug claims to an episode based on the NDC code on the drug claim and the timing of the episodes. ${ }^{11}$

However, one downside of using these algorithms is that they are also considered a "black box" in the sense that they rely entirely on the grouper software developer's expertise. The ETG Symmetry grouper is applied to one calendar year of data at a time. Although this limits the amount of information used for each person (since we often observe multiple years), it also avoids potential biases that may occur if the grouper is not applied symmetrically across all years. ${ }^{12}$

Finally, it is important to note that while the ETG groupings are based mostly on ICD-9 disease codes, we aggregate the ETGs to Major Practice Categories, as is done in Aizcorbe and Nestoriak. However, this is solely for presentation purposes, and the practice category of the physician on the claim has little bearing into which ETG the claim is assigned. Rather, we group entire episodes to practice categories after the ETGs have been assigned to each claim.

For all measures but the ECI, demographic weights are applied to each individual to adjust for differences in age, sex, and region across populations, so the expenditure estimates may be comparable across years. Specifically, enrollees in each year are assigned weights so the weighted population has an age and sex distribution that is identical to that of the U.S. commercially insured population in 2007. ${ }^{13}$ To look at the growth in expenditure due to population growth and shifts, we also calculate total weighted

\footnotetext{
${ }^{11}$ See Rosen et al. (2012), Dunn et al. (2014) for more detailed information about how the grouper works and for information about how the ETG grouper relates to other groupers. For instance, Dunn et al. (2014) compares the robustness of their results using the ETG to other grouping methods, including the CCS codes used by Roehrig and Rousseau.

${ }^{12}$ The ETG grouper allocates each record into one of over 500 disease groups. To symmetrically process the data, we apply the ETG episode grouper on the claims data one year at a time. Applying the grouper one year at a time can split episodes into two, which may lead to an overstatement of the count of episodes and an understatement to the average price of an episode. However, applying the grouper across years leads the grouper to incorporate more information in later years, introducing an artificial time-trend to the results. We explore the robustness of the estimates to various grouping methodologies in Dunn et al. (2014).

${ }^{13}$ We use 2007 as the base to look at a population of individuals and their diseases that is more similar to our current population distribution. Similar results are found if we use the 2003 population as the base.
} 
spending over this period in a way that allows populations to vary.

\subsection{Service Price, Utilization, and Episodes}

The number of episodes is a simple count of the total number of episodes of a medical disease that end in the sample period. Total episode expenditures are measured as the total dollar amount received by all providers for the services used to treat an episode of a specific disease (including both out-of-pocket payments and amounts paid by insurance firms).

Service utilization measures are created for each type of service based on the definition of a service within that service type. The service-type categories are inpatient hospital, outpatient hospital, physician, prescription drug, and other. Measuring service utilization is not a straightforward task since the definition of "service" is a bit ambiguous and there are a variety of ways that one could define it across various service types. Ideally, we would like the definition of a specific service to depend on how the price of that service is typically set and paid. For example, for physician services, individuals pay a unique price for each procedure done to them (that is, the insurer and the patient together pay this amount), whereas the prices paid to facilities are often set based on the treated disease. Next we describe how the quantity of services is measured for each service type.

\subsubsection{Measuring the Quantity of Service by Service Type}

For each claim line in the data, we first categorize it by place of service, which determines the service-type category. For each category, the following steps describe how the amount is determined for each visit, where a visit is defined by the enrollee and the date of service or admission:

Physician office - Physician visits are priced based on procedures performed in a physician's office. Since not all procedures are equivalent, each procedure is weighted to reflect the intensity of the service. For the Medicare payment system, Relative Value Units (RVUs) define reimbursement rates and are intended to capture the intensity of the services provided. In that spirit, we proxy for the intensity of service by using the average 
prices for each Current Procedural Terminology (CPT-4) code and modifier code. The total quantity of services performed in an office is then computed by summing over these RVU amounts. More precisely, the total amount of services from a physician office visit is computed as $q_{\text {office }}=\sum_{c p t \in V i s i t} \bar{p}_{c p t, o f f i c e}$, where $c p t \in$ Visit is a complete list of CPT procedures performed during the visit in an office setting and $\bar{p}_{c p t, o f f i c e}$ is the base price for procedure code, $c p t$. The base group price, $\bar{p}_{c p t, o f f i c e}$, is computed as the average price in the data for that procedure code and modifier code across all time periods. Since most insurers set prices from a base price schedule (e.g., 10 percent above Medicare rates), one can think of the price of a cpt code at time $t$ as the base price multiplied by a scalar price, $\alpha_{t}$, where $p_{c p t}^{t}=\alpha_{t} \bar{p}_{c p t}$. For instance, if a CPT code that equals 99213 indicating a 15-minute established patient office visit has an average price of $\$ 100$, its value will be 100 RVUs (i.e., $\bar{p}_{99213}=100$ ). It should be clear that the RVU amount is a measure of utilization and not price. To see this, if the fee on a 15 -minute office visit is $\$ 120$ at time $t\left(p_{99213}^{t}=\$ 120\right)$, then the price of the service will be calculated as $\$ 120 / 100 \mathrm{RVU}=1.2$ $\$ /$ RVU (i.e., $\left.\alpha_{t}=\frac{p_{c p t}^{t}}{\bar{p}_{c p t}}\right) \cdot{ }^{14}$

Hospital inpatient - Inpatient hospital stays not only consist of facility fees paid to the hospital, but also fees paid to the physician. A variable in the claims data distinguishes these two types of payments. For the portion of fees paid to the hospital, the amount of services is measured as the average dollar amount for an inpatient stay for the observed disease. For the portion of fees paid to the physician, we assign an RVU in the same way that we calculate an RVU in an office setting. The total amount of services performed in an inpatient setting is calculated by adding the physician and facility amounts. Specifically, $q_{\text {inpatient }}=\bar{p}_{\text {d,inpatient }}+\sum_{c p t \in V i s i t} \bar{p}_{\text {cpt,inpatient }}$ where $\bar{p}_{\text {d,inpatient }}$ is the base price for inpatient facility claims for disease $d$, where the base price is the average price in the data across all time periods for a visit to an inpatient facility for treating disease $d$. The term $\sum_{c p t \in V i s i t} \bar{p}_{c p t, \text { inpatient }}$ is the amount calculated for the physician portion of the bill and is computed in a manner identical to the physician office category, but is based on only physician claims in an inpatient setting.

Hospital outpatient - Outpatient hospital visits are calculated in an identical fashion

\footnotetext{
${ }^{14}$ This methodology for calculating utilization for physician services is identical to that conducted by Dunn and Shapiro (2012).
} 
to the inpatient hospital visits. That is, the facility amount is calculated based on the average outpatient visit for that disease, and the doctor's portion of the total amount is calculated based on the average payment for the procedure codes in an outpatient setting.

Prescription drugs - The amount of the prescription drug varies based on the molecule, the number of pills in the bottle, the strength of the drug, and the manufacturer. An 11-digit National Drug Code (NDC) uniquely identifies the manufacturer, the strength, dosage, formulation, package size, and type of package. To capture these differences, we calculate the average price for each NDC code. This means we treat branded and generic products that contain the same active molecule as distinct drugs. The average price for each NDC code represents the amount of the service used. Specifically, the amount of drug services used is $q_{d r u g}=\sum_{N D C \in V i s i t} \bar{p}_{N D C}$, where $N D C \in V i$ sit is a complete list of NDC codes purchased from a visit to a pharmacy and $\bar{p}_{N D C}$ is the base price for a specific NDC code. The base price for each NDC is computed as the average price in the data.

All other - The other category primarily includes ambulatory care, independent labs, and emergency room visits. For these services, if no procedure code is available, the amount of each category is measured as the average cost for a visit to that particular place of service for treating a particular disease (for example, the average cost of an ambulatory care visit to treat ischemic heart disease). For cases where procedure codes are available, we use the average cost of that procedure code for that place of service.

Our decomposition relies on the institutional feature that insurers and providers typically negotiate from a percentage of a base fee schedule (for example, 10 percent above Medicare rates). ${ }^{15}$ As our measure of service price can be intuited as the expenditures from a visit divided by a proxy for a "RVU", it can also be thought of as a percentage amount from a base (or average) payment - a measure close to how prices are actually set. For this reason, these measures of service quantity subsequently allow us to create service prices that correspond well with how fees are negotiated in the marketplace. In other words, our approach attempts to construct a unit value index that reflects the

\footnotetext{
${ }^{15}$ In a survey of 20 health plans conducted by Dyckman \& Associates, all 20 health plan fee schedules were influenced by the Medicare fee schedule. That is, a resource-based relative value scale (RBRVS), essentially adopting Medicare's base fee schedule.
} 
heterogeneity in how goods and services are actually priced. ${ }^{16}$ It can also be shown that if pricing is set based on a percentage of a set fee schedule then our index is equivalent to an index that prices specific procedures. See Dunn, Shapiro, and Liebman (2014) and the associated appendix for additional details.

\subsection{Summary Statistics}

Table 1 provides some basic descriptive statistics for the selected commercially insured population of the MarketScan data. Each enrollee is assigned a population weight based on age, gender, and location so that the number of enrollees represents the actual number of commercially insured enrollees measured by the Current Population Survey (CPS). Note that this table reports figures where weights are applied, so that the population changes and grows with the actual commercially insured population. ${ }^{17}$ As described above, when calculating the DECI and subsequent decomposition indexes, we hold fixed the age, gender, and location. There are 455 ETG disease categories in the sample, ${ }^{18}$ representing $\$ 454.4$ billion for 180.5 million enrollees in 2003 , growing to $\$ 589.4$ billion and 182.5 million enrollees in 2007. This growth is accompanied by a growth in the number of episodes from 2.7 per enrollee in 2003 to 3.0 per enrollee in 2007. The average

\footnotetext{
${ }^{16}$ Note that our approach differs from Bundorf et al. (2009) which also studied individual service prices over time, though not at the disease level. Since they do not calculate disease-level prices, they are able to separately price each individual CPT code and NDC code. In contrast, this is not possible in a disease-based framework because not all CPT codes and NDC codes are observed for every disease across all years.

It should also be noted that there are alternative methods for pricing medical services that may not be reflected in the methods applied here. For instance, for Medicare patients, outpatient hospital facility services are often priced based on the Ambulatory Payment Classification system and this method is also used by many commercial insurers.

${ }^{17}$ Our weights were constructed using data from http://www.census.gov/cps/data/cpstablecreator.html.

${ }^{18}$ Severity adjustment increases the number of disease categories to 682. About 19 percent of expenditures are not assigned to any ETG disease category. Ungrouped claims include screening for diseases and other records that cannot be assigned a category. The ungrouped claims are removed from our analysis. If we do not adjust for severity, then the ungrouped share falls to 13 percent, but the results stay the same.
} 
age grew slightly from 32.3 to 32.9 over the sample period. The table shows that this growth is primarily from an increased percentage of enrollees over the age of 55 .

Table 1. Summary Statistics

\begin{tabular}{l|c|c}
\multicolumn{2}{c}{2003} & 2007 \\
\hline \hline Expenditure (Billions) & $\$ 454.39$ & $\$ 589.35$ \\
Enrollees (Millions) & 180.58 & 182.53 \\
Expenditure per Capita (Enrollee) & $\$ 2,516$ & $\$ 3,229$ \\
Episodes per Capita (Enrollee) & 2.71 & 2.96 \\
Expenditure per Episode & $\$ 929$ & $\$ 1,092$ \\
Percent Male & $49.5 \%$ & $49.6 \%$ \\
Average Age & 32.3 & 32.9 \\
< Age 18 & $27.3 \%$ & $26.3 \%$ \\
Age 18 - Age 24 & $9.6 \%$ & $9.6 \%$ \\
Age 25 - Age 34 & $14.5 \%$ & $14.7 \%$ \\
Age 35 - Age 54 & $36.3 \%$ & $35.6 \%$ \\
> Age 55 & $12.2 \%$ & $13.8 \%$
\end{tabular}

\section{Results}

\subsection{Aggregated Indexes}

We begin our analysis by examining aggregated time-specific indexes, which provide information about the entire commercial health-care market for a given year. Specifically, we create $E C I_{t}, D E C I_{t}, P R E V_{t}, M C E_{t}, S P I_{t}, S U I_{t}$, and $D e m_{t}$ by weighting each disease-specific index by the expenditure share of that disease in the base period. The top panel of Figure 1 displays the aggregated expenditures per capita index $\left(E C I_{t}\right)$ along with its decomposition between the demographic residual $\left(D e m_{t}\right)$ and the demographically fixed expenditures per capita index $\left(D E C I_{t}\right)$. The $E C I$ grew 6.4 percent per year from 2003 to 2007 - a total of 28 percent over the four years. Demographic factors accounted for about a tenth of this growth, as the demographic residual grew by only 3 percent over the four years and the DECI grew by 25 percent.

Figure 1. Aggregated Indexes 

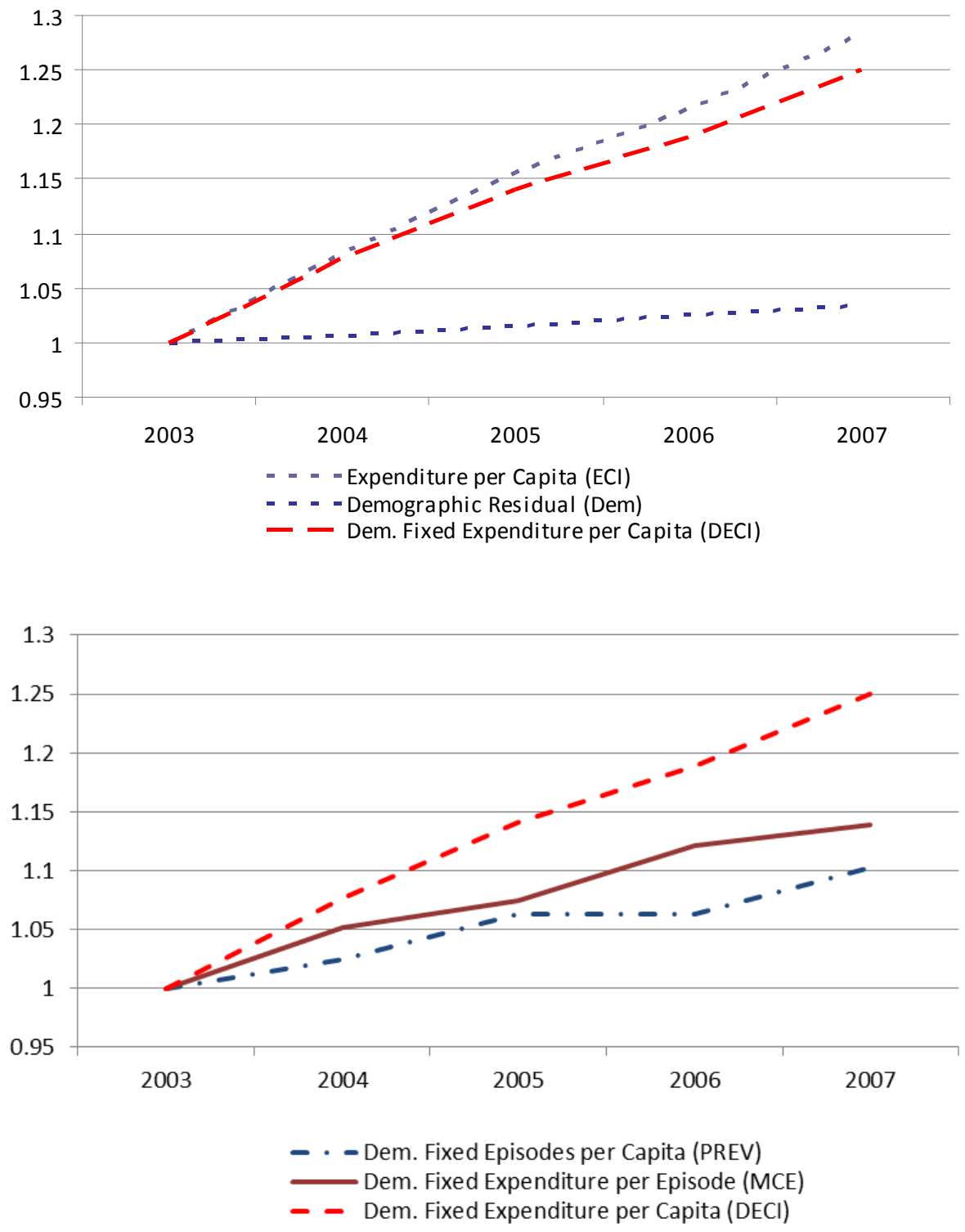


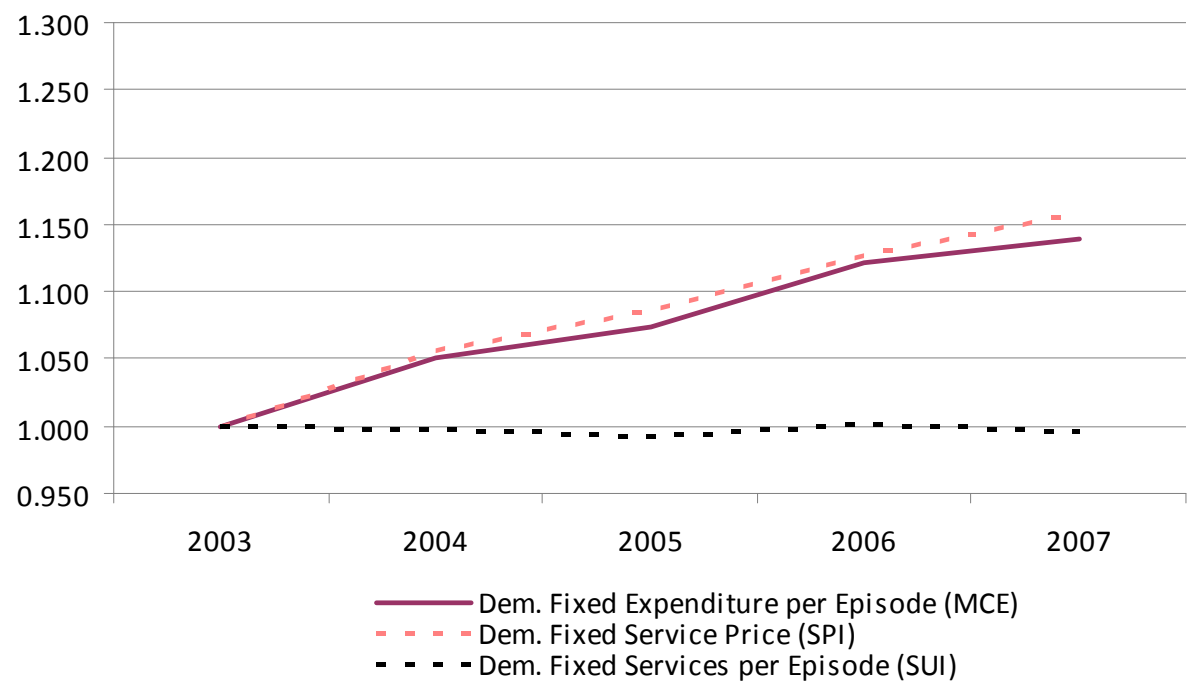

The second panel displays the $D E C I_{t}$ along with its decomposition between the $M C E_{t}$ and $P R E V_{t}$. Growth in $M C E_{t}$ represents about 56 percent of the total growth in the $D E C I$ while growth in the prevalence index accounted for about 41 percent. Specifically, the $M C E_{t}$ grew by 3.3 percent per year while the $P R E V_{t}$ grew by 2.5 percent. Note that the growth in the aggregate $P R E V_{t}$ may reflect either an increase in treated prevalence or a shift toward more expensive diseases. Finally, the third panel decomposes the $M C E_{t}$ between service prices $\left(S P I_{t}\right)$ and service utilization $\left(S U I_{t}\right)$. These aggregate indexes show that the cost of treatment growth is entirely due to changes in the underlying prices of the services and not the quantity of services being provided per episode. To be more precise, the $S P I_{t}$ grew by 3.8 percent per year (15.9 percent over the sample period) while the $S U I_{t}$ fell just 0.4 percent over the sample period.

All spending is calculated in nominal terms, but because health care has taken up an increasing share of GDP, it is interesting to investigate the contributing factors to growth after accounting for national inflation figures. Previous researchers also accounted for inflation, including Roehrig and Rousseau (2011) and Bundorf et al. (2009), two papers that have looked at decomposing expenditure growth into components of price and utilization. After accounting for inflation by the PCE deflator (which grew by 11.5 percentage points between 2003 and 2007), we find that real service prices grew by 1 
percent per year - about 4 percent from 2003 to 2007. This is consistent with the finding in Bundorf et al. (2009) who also look at commercial markets and find very little service price growth relative to inflation over the 2001-2006 time period for the commercial sector. Another way of stating this is that, of the 28 percent expenditures per capita $\left(E C I_{t}\right)$ growth from 2003 to 2007, 15.1 percentage points were attributable to things other than PCE inflation. Two-thirds of those 15.1 percentage points are attributable to increasing prevalence of treated diseases ${ }^{19}$ and one-fifth was attributable to demographic shifts. $^{20}$

\subsection{Major Practice Categories}

The aggregated indexes discussed above suggest that expenditure growth is occurring for two primary reasons: (1) growth in service prices and (2) growth in the prevalence of treated diseases. As treatments and changes in treatments are unique to each disease, ${ }^{21}$ we next show indexes specific to 22 Major Practice Categories (MPC), the ETG aggregate

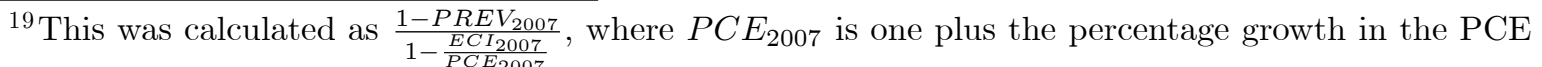
deflator between 2003 and 2007.

${ }^{20} \mathrm{At}$ first glance 1 year increase in the average age seems too small to lead to a 3 percent increase in expenditures, but a more careful look at the data highlights the considerable differences in costs for those in different age groups. For example, the composition of the population shifts so those over 55 account for $1.6 \%$ more of the population. Likewise, those under 18 account for $1 \%$ less of the share of the population. This can make a significant impact since those over-55 are more than 4 times as expensive as those under-18, on average. Back of the envelope calculations seem to suggest that these small changes in the composition of the population are sufficient to cause a $3 \%$ increase in the expenditure growth.

The results presented here are quite distinct from the results of Roehrig and Rousseau (2011), who use the Medical Expenditure Panel Survey data and find that, even after accounting for inflation, expenditure per capita growth is primarily driven by expenditures per episode (i.e., $M C E$ ) and not prevalence, with the growth in the expenditure per episode accounting for 75 percent of expenditure growth. We find that expenditure per episode accounts for only about 20 percent of inflation-adjusted growth in the commercial sector. The study of a distinct time period may be a key factor causing these different findings. These differences warrant future investigation.

${ }^{21}$ This has been demonstrated in prior work by Thorpe, Florence, and Joski (2009), Roehrig and Rousseau (2011), Aizcorbe and Nestoriak (2011), Dunn et al. (2012a), and Dunn, Shapiro, and Liebman (2012).
} 
categories provided by Optum for the Symmetry ETG grouper. ${ }^{22}$ Each category is calculated as a weighted average of the many underlying disease-severity specific indexes in that category, where the weights are the proportions of expenditure shares in $2003 .^{23}$ These broader categories give some sense of where expenditure growth is occurring.

We report MPCs ordered according to the size of their expenditure share in Table 2. The largest category is orthopedics and rheumatology, which accounted for 16.6 percent of spending in 2003. Spending in this category grew from $\$ 418$ per capita in 2003 to $\$ 558$ per capita in 2007 - an increase of 33 percent as indicated by the 2007 ECI of 1.33. Orthopedics' share of expenditure growth (19.6 percent) exceeded its share of 2003 expenditure (16.6 percent), which is attributable to the fact that this diagnostic category grew faster than average. We can assess the sources of this growth by examining the 2007 indexes. For instance, demographic shift accounted for 3 points of the 33-percentagepoint increase in expenditures per capita, treated prevalence accounted for another 12 percentage points, service prices accounted for 15 percentage points, service utilization 3 percentage points, and the cross-term is zero.

\footnotetext{
${ }^{22}$ These categories align with specialties, but they have no bearing on how the grouper processed the data. A visit to a general practitioner would be treated as identical to a visit to a specialist, if the same diagnoses and procedures were performed.

${ }^{23}$ For instance, the aggregated $E C I$ for Cardiology was calculated as $E C I_{C a r d, t}=\sum_{d \in \text { Card }} \omega_{d} \cdot E C I_{d, t}$ where $\omega_{d}=\frac{C_{d, 0}}{\sum_{d \in \text { Card }} C_{d, 0}}$ and Card is the set of diseases in the Major Practice Category: Cardiology.
} 
Table 2. Major Practice Category

\begin{tabular}{|c|c|c|c|c|c|c|c|c|c|c|c|}
\hline & \multirow{2}{*}{$\begin{array}{c}2003 \\
\text { Expenditure } \\
\text { per Capita }\end{array}$} & \multirow{2}{*}{$\begin{array}{c}2007 \\
\text { Expenditure } \\
\text { per Capita } \\
\end{array}$} & \multirow{2}{*}{\multicolumn{2}{|c|}{\begin{tabular}{||cc|}
2003 Share & Share of \\
of Total & Expenditure \\
Expenditure & Growth
\end{tabular}}} & \multicolumn{7}{|c|}{2007 Indexes } \\
\hline & & & & & $\mathrm{ECl}$ & Dem & $\mathrm{DECl}$ & PREV & MCE & $\mathrm{SPI}$ & SUI \\
\hline Orthopedics \& rheumatology & $\$ 418$ & $\$ 558$ & $16.6 \%$ & $19.6 \%$ & 1.33 & 1.03 & 1.30 & 1.12 & 1.17 & 1.15 & 1.03 \\
\hline Cardiology & $\$ 296$ & $\$ 348$ & $11.8 \%$ & $7.3 \%$ & 1.18 & 1.07 & 1.11 & 1.04 & 1.06 & 1.16 & 0.93 \\
\hline Gastroenterology & $\$ 228$ & $\$ 304$ & $9.1 \%$ & $10.6 \%$ & 1.33 & 1.04 & 1.29 & 1.11 & 1.17 & 1.17 & 1.01 \\
\hline Gynecology & $\$ 181$ & $\$ 222$ & $7.2 \%$ & $5.9 \%$ & 1.23 & 1.02 & 1.22 & 1.01 & 1.20 & 1.19 & 1.01 \\
\hline Endocrinology & $\$ 169$ & $\$ 236$ & $6.7 \%$ & $9.4 \%$ & 1.40 & 1.05 & 1.34 & 1.27 & 1.07 & 1.17 & 0.93 \\
\hline Otolaryngology & $\$ 163$ & $\$ 186$ & $6.5 \%$ & $3.2 \%$ & 1.14 & 1.00 & 1.14 & 1.03 & 1.11 & 1.13 & 1.00 \\
\hline Neurology & $\$ 147$ & $\$ 195$ & $5.8 \%$ & $6.7 \%$ & 1.33 & 1.03 & 1.30 & 1.10 & 1.19 & 1.21 & 0.99 \\
\hline Pulmonology & $\$ 119$ & $\$ 143$ & $4.7 \%$ & $3.4 \%$ & 1.20 & 1.04 & 1.16 & 1.01 & 1.16 & 1.20 & 0.97 \\
\hline Psychiatry & $\$ 119$ & $\$ 150$ & $4.7 \%$ & $4.3 \%$ & 1.26 & 1.00 & 1.26 & 1.13 & 1.12 & 1.15 & 1.01 \\
\hline Dermatology & $\$ 115$ & $\$ 149$ & $4.6 \%$ & $4.7 \%$ & 1.29 & 1.02 & 1.28 & 1.08 & 1.18 & 1.16 & 1.03 \\
\hline Obstetrics & $\$ 112$ & $\$ 139$ & $4.4 \%$ & $3.9 \%$ & 1.25 & 0.99 & 1.26 & 1.08 & 1.17 & 1.15 & 1.02 \\
\hline Urology & $\$ 91$ & $\$ 116$ & $3.6 \%$ & $3.5 \%$ & 1.27 & 1.05 & 1.22 & 1.12 & 1.11 & 1.14 & 0.98 \\
\hline Hematology & $\$ 62$ & $\$ 82$ & $2.5 \%$ & $2.8 \%$ & 1.32 & 1.04 & 1.28 & 1.11 & 1.15 & 1.22 & 0.96 \\
\hline Preventive $\&$ administrative & $\$ 59$ & $\$ 97$ & $2.4 \%$ & $5.3 \%$ & 1.64 & 1.02 & 1.62 & 1.29 & 1.26 & 1.14 & 1.11 \\
\hline Hepatology & $\$ 59$ & $\$ 68$ & $2.3 \%$ & $1.2 \%$ & 1.15 & 1.03 & 1.12 & 0.99 & 1.12 & 1.17 & 0.96 \\
\hline Ophthalmology & $\$ 40$ & $\$ 50$ & $1.6 \%$ & $1.4 \%$ & 1.25 & 1.06 & 1.19 & 1.13 & 1.05 & 1.09 & 0.98 \\
\hline Infectious diseases & $\$ 34$ & $\$ 48$ & $1.3 \%$ & $1.9 \%$ & 1.41 & 1.03 & 1.38 & 1.15 & 1.18 & 1.12 & 1.06 \\
\hline Nephrology & $\$ 34$ & $\$ 47$ & $1.3 \%$ & $1.9 \%$ & 1.39 & 1.06 & 1.33 & 1.49 & 0.90 & 0.91 & 1.00 \\
\hline Neonatology & $\$ 25$ & $\$ 36$ & $1.0 \%$ & $1.5 \%$ & 1.43 & 1.12 & 1.32 & 1.14 & 1.17 & 1.13 & 1.03 \\
\hline Isolated signs \& symptoms & $\$ 19$ & $\$ 21$ & $0.7 \%$ & $0.3 \%$ & 1.12 & 1.01 & 1.11 & 1.00 & 1.11 & 1.10 & 1.02 \\
\hline Late effects, environmental trauma & $\$ 14$ & $\$ 18$ & $0.6 \%$ & $0.6 \%$ & 1.30 & 1.02 & 1.27 & 0.96 & 1.34 & 1.29 & 1.04 \\
\hline Chemical dependency & $\$ 12$ & $\$ 18$ & $0.5 \%$ & $0.7 \%$ & 1.42 & 1.00 & 1.41 & 1.38 & 1.06 & 1.10 & 0.99 \\
\hline Total & $\$ 2,516$ & $\$ 3,229$ & $100.0 \%$ & $100.0 \%$ & 1.28 & 1.03 & 1.25 & 1.10 & 1.14 & 1.16 & 1.00 \\
\hline
\end{tabular}

One striking feature of Table 2 is the substantial growth in preventive health services. This category represented only 2.4 percent of 2003 expenditures but 5.3 percent of expenditure growth between 2003 and 2007. This category appears to be growing out of proportion for two reasons: increased prevalence of treatment (29 percent growth) as well as a large increase in service utilization (11 percent growth). Looking more deeply at this category, it appears that expenditures are driven primarily by more individuals receiving routine exams. One question raised is whether the greater prevalence and utilization of preventive services ultimately leads to lower overall health expenditures and better health outcomes. This is especially important given that the recent health care reform passed in the Patient Protection and Affordable Care Act encourages the use of preventive care services. Although more preventive care services are likely to lead to expenditures increasing in the short term, it is unclear what the long-term effects may be on both future health and expenditures.

It is especially interesting to note that many of the other diagnostic categories do 
not grow in proportion to their expenditure share. For example, cardiology diseases accounted for around 12 percent of spending in 2003, but only 7.3 percent of the expenditure growth between 2003 and 2007. Although service prices in this area are growing at a similar pace with other disease categories (around 16 percent) expenditure growth is kept in check by slower-than-average growth in prevalence as well as declining service utilization. Endocrinological diseases, many of which are major contributors to cardiovascular diseases, also show a decline in service utilization, however they show much faster growth in treated disease prevalence. For this reason, expenditures per capita rose twice as fast for endocrinological diseases than for cardiology diseases.

For many disease conditions, we see important differences between the disease price (MCE) and the prices of the underlying services (SPI). These differences may be of significant economic importance. For instance, if the SPI growth exceeds the MCE, this indicates that the price of disease treatment is growing slower than the rate implied by traditional inflation measures. To better understand the difference between SPI and MCE indexes, we apply an additional decomposition that reports the difference between the SPI and MCE indexes by service type, $s .{ }^{24}$ The decomposition equation is

$$
\begin{gathered}
M C E_{d, t}=S P I_{d, t}+\left(M C E_{d, t}-S P I_{d, t}\right)=S P I_{d, t}+\sum_{s}\left(M C E_{d, t, s}-S P I_{d, t, s}\right)\left(\operatorname{Exp}_{\text {. Share }} \text { Sh, }\right) \\
=S P I_{d, t}+\sum_{s}\left(M C E_{d, t, s}-S P I_{d, t, s}\right)\left(\frac{q_{d, 0, s} \cdot p_{d, 0, s}}{\sum_{s} q_{d, 0, s} \cdot p_{d, 0, s}}\right)
\end{gathered}
$$

The term $\left(M C E_{d, t, s}-S P I_{d, t, s}\right)\left(\operatorname{Exp}_{\text {. Share }}{ }_{d, 0, s}\right)$ represents service category $s$ 's contribution to the difference between the $M C E$ and $S P I$ indexes. To gain some additional intuition for this equation, we take the decomposition from equation (10), but remove the cross term, which gives the approximate relationship $M C E_{d, t} \approx S P I_{d, t}+$

\footnotetext{
${ }^{24}$ This same decomposition is applied in Dunn, Liebman, and Shapiro (2014b). The only difference is that here we apply it to the full sample of diseases, while in Dunn, Liebman, and Shapiro (2014b), looked only at disease conditions with more than 10,000 episodes.
} 
Table 3. Comparison of MCE and SPI and sources of differences, $2003-2007$

\begin{tabular}{c||c|cccccc}
\multicolumn{1}{c|}{} & \multicolumn{7}{c}{ Contribution to MCE-SPI difference } \\
\cline { 3 - 8 } \multicolumn{1}{c|}{} & \multicolumn{1}{c}{} & \multicolumn{7}{c}{ Inpatient } & Outpatient & Physician & & Brand & Generic \\
Hospital & Hospital & Office & Other & Drugs & Drugs \\
\hline \hline Orthopedics \& rheumatology & 0.017 & -0.026 & 0.001 & 0.038 & 0.021 & -0.036 & 0.019 \\
Cardiology & -0.097 & -0.101 & -0.005 & 0.017 & -0.001 & -0.028 & 0.021 \\
Gastroenterology & -0.003 & -0.035 & -0.008 & 0.014 & 0.041 & -0.029 & 0.015 \\
Gynecology & 0.010 & -0.044 & 0.029 & 0.030 & 0.002 & -0.016 & 0.009 \\
Endocrinology & -0.092 & -0.090 & 0.000 & -0.001 & 0.008 & -0.055 & 0.047
\end{tabular}

$S U I_{d, t}-1$. Applying this approximation, we substitute $S U I-1$ for $M C E-S P I$ into equation (10); then the decomposition by service category is $M C E_{d, t} \approx S P I_{d, t}+$ $\sum_{s}\left(S U I_{d, t, s}-1\right)\left(\operatorname{Exp}_{\text {. Share }}{ }_{d, 0, s}\right)$. From this approximate decomposition, one can see that the difference between the two indexes will primarily depend on the change in utilization of the different services and the corresponding expenditure share of the service category.

Table 3 shows the contribution of each service type, $s$, to the difference between the MCE and SPI (applying the exact decomposition 10). Table 3 shows several clear patterns across services for the top five spending diseases. ${ }^{25}$ First, nearly every disease category shifts away from spending on inpatient services, which is especially large for cardiology and endocrinology conditions. This savings from reduced utilization on inpatient services is partly offset by an increase in the utilization of physician services for most disease categories. For drug services, we observe a shifting away from branded drugs, leading to a relative decline in the MCE, and we see an increase in generic drugs, contributing to an increase in the MCE. Combined, the shifting away from branded drugs toward generics causes a net decline in the MCE relative to the SPI for these top five diseases. $^{26}$

\footnotetext{
${ }^{25}$ See Dunn, Shapiro, and Liebman (2014) for a more complete discussion of this topic.

${ }^{26}$ Although generics are considerably cheaper than branded drugs, the total difference may not be reflected in the tables. Generic drugs tend to be cheaper, pulling down the cost of treatment, but the lower cost of generics may also imply that consumers are purchasing more generic prescription drugs.
} 


\subsection{Disease-Specific Indexes}

Our methodology for decomposing expenditure growth may be used to drill down even further to the specific disease-severity level. Due to the large number of diseases, there are numerous dimensions in which we could look at the growth in expenditures. In the following section, we demonstrate how the methodology may be applied to a few areas of spending. Specifically, we focus on those diseases that are included in some of the larger MPCs and on the treatment of neoplasms (that is, benign and malignant tumors).

\subsubsection{Cardiology and Endocrinology}

Table 4. Cardiology and Endocrinology

\begin{tabular}{|c|c|c|c|c|c|c|c|c|c|}
\hline & \multirow{2}{*}{$\begin{array}{c}2003 \\
\text { Expenditure } \\
\text { per Capita }\end{array}$} & \multirow{2}{*}{$\begin{array}{c}2007 \\
\text { Expenditure } \\
\text { per Capita }\end{array}$} & \multicolumn{7}{|c|}{2007 Indexes } \\
\hline & & & $\mathrm{ECl}$ & DEM & $\mathrm{DECl}$ & PREV & MCE & SPI & SUI \\
\hline Ischemic heart disease 1 & $\$ 55$ & $\$ 54$ & 0.98 & 1.07 & 0.91 & 0.95 & 0.96 & 1.14 & 0.86 \\
\hline Hypertension 1 & $\$ 48$ & $\$ 64$ & 1.33 & 1.06 & 1.27 & 1.14 & 1.11 & 1.13 & 1.01 \\
\hline Diabetes 1 & $\$ 43$ & $\$ 68$ & 1.58 & 1.09 & 1.48 & 1.28 & 1.16 & 1.17 & 1.01 \\
\hline Ischemic heart disease 2 & $\$ 30$ & $\$ 32$ & 1.07 & 1.08 & 0.99 & 1.09 & 0.91 & 1.09 & 0.84 \\
\hline Hyperlipidemia, other 1 & $\$ 26$ & $\$ 37$ & 1.43 & 1.08 & 1.35 & 1.29 & 1.05 & 1.16 & 0.95 \\
\hline Ischemic heart disease 3 & $\$ 24$ & $\$ 24$ & 1.01 & 1.07 & 0.94 & 0.88 & 1.07 & 1.20 & 0.90 \\
\hline Ischemic heart disease 4 & $\$ 22$ & $\$ 23$ & 1.05 & 1.07 & 0.98 & 0.91 & 1.08 & 1.20 & 0.90 \\
\hline Obesity 2 & $\$ 17$ & $\$ 15$ & 0.89 & 1.00 & 0.88 & 1.55 & 0.57 & 1.04 & 0.54 \\
\hline Cardiovascular diseases signs \& symp. 1 & $\$ 16$ & $\$ 18$ & 1.13 & 1.02 & 1.11 & 1.02 & 1.09 & 1.11 & 1.00 \\
\hline Diabetes 4 & $\$ 13$ & $\$ 17$ & 1.27 & 1.03 & 1.23 & 1.04 & 1.19 & 1.20 & 1.00 \\
\hline
\end{tabular}

Table 4 reports the expenditure decomposition for the ten largest diseases by spending in the two major practice categories of cardiology and endocrinology. The number that appears after each disease description is the severity level, ranging between 1 to 4 for many diseases, with a higher number indicating a greater severity. The table shows there have been large increases in the prevalence of treated hypertension, hyperlipidemia, diabetes, and obesity. This may correspond to changing lifestyles or eating habits of the 
commercially insured population. However, these four diseases are also major contributors to ischemic heart disease, which has strikingly shown a decline in treated prevalence. ${ }^{27}$ This may indicate that people are seeking treatment earlier, before ischemic heart disease arises, perhaps reflecting a growing awareness of this medical condition. Indeed, evidence from the National Health and Nutrition Examination Survey shows very rapid growth in treated prevalence for diabetes, hyperlipidemia, and hypertension, even though the underlying clinical prevalence has remained relatively flat for these conditions. $^{28}$

Also of note is that spending for low-severity ischemic heart disease has been declining over the sample period. In fact, were it not for an aging commercial population, spending per capita would have fallen by almost 10 percent between 2003 and 2007. This decline in spending is mostly attributable to the large decline in service utilization. This finding is also consistent with the work of Cutler et al. (1998), who find the quality-adjusted prices for treating heart attacks to be declining. As discussed in the previous section, this shift in utilization is attributable to the shift from inpatient to outpatient services in the treatment of heart disease.

\footnotetext{
${ }^{27}$ The decline in treated prevalence may be seen by averaging over the different severities of ischemic heart disease based on expenditures per capita. A study by the Centers for Disease Control and Prevention has also reported a decline in the prevalence of ischemic heart disease for the 2006 to 2010 period based on the Behavioral Risk Factor Surveillance System surveys (http://www.cdc.gov/mmwr/preview/mmwrhtml/mm6040a1.htm).

${ }^{28}$ Specific values of these trends from the National Health and Nutrition Examination Survey are reported in Roehrig and Rousseau (2011).
} 


\subsubsection{Gastroenterology}

Table 5. Gastroenterology

\begin{tabular}{|c|c|c|c|c|c|c|c|c|c|}
\hline & \multirow{2}{*}{\begin{tabular}{|c}
2003 \\
Expenditure \\
per Capita
\end{tabular}} & \multirow{2}{*}{$\begin{array}{c}2007 \\
\text { Expenditure } \\
\text { per Capita } \\
\end{array}$} & \multicolumn{7}{|c|}{2007 Indexes } \\
\hline & & & $\mathrm{ECl}$ & DEM & $\mathrm{DECl}$ & PREV & MCE & SPI & SUI \\
\hline Inflammation of esophagus 1 & $\$ 27$ & $\$ 29$ & 1.09 & 1.02 & 1.07 & 1.06 & 1.01 & 1.12 & 0.92 \\
\hline Gastroenterology diseases signs \& symptoms 1 & $\$ 23$ & $\$ 33$ & 1.41 & 1.03 & 1.39 & 1.16 & 1.20 & 1.15 & 1.05 \\
\hline Non-malignant neoplasm of intestines \& abdomen 1 & $\$ 20$ & $\$ 27$ & 1.34 & 1.08 & 1.26 & 1.16 & 1.08 & 1.08 & 1.02 \\
\hline Hernias, except hiatal 1 & $\$ 10$ & $\$ 12$ & 1.19 & 1.03 & 1.16 & 1.02 & 1.14 & 1.19 & 0.96 \\
\hline Appendicitis 1 & $\$ 9$ & $\$ 12$ & 1.41 & 0.99 & 1.42 & 1.15 & 1.24 & 1.20 & 1.02 \\
\hline Inflammatory bowel disease 3 & $\$ 7$ & $\$ 11$ & 1.51 & 0.99 & 1.52 & 1.28 & 1.19 & 1.18 & 1.03 \\
\hline Malignant neoplasm of rectum or anus 2 & $\$ 6$ & $\$ 9$ & 1.45 & 1.08 & 1.37 & 0.93 & 1.47 & 1.41 & 1.05 \\
\hline Inflammation of esophagus 2 & $\$ 5$ & $\$ 6$ & 1.12 & 1.06 & 1.06 & 1.12 & 0.95 & 1.12 & 0.86 \\
\hline Bowel obstruction 1 & $\$ 5$ & $\$ 7$ & 1.26 & 1.05 & 1.22 & 1.04 & 1.16 & 1.13 & 1.03 \\
\hline Malignant neoplasm of rectum or anus 3 & $\$ 5$ & $\$ 8$ & 1.55 & 1.10 & 1.45 & 0.95 & 1.54 & 1.49 & 1.04 \\
\hline
\end{tabular}

Similar to cardiological and endocrinological diseases, gastroenterological diseases saw a shift in prevalence to earlier stage-of-illness treatment. Table 5 shows that prevalence in "gastroenterology signs and symptoms 1" and "non-malignant neoplasm of intestines and abdomen 1" (e.g., benign polyps) both saw 16 percent growth in prevalence over the sample period. These two diseases represented one-fifth of gastroenterological expenditures in 2003 and grew by 41 and 34 percent, respectively, over the sample period. Endoscopic procedures (mainly colonoscopy) represented the largest share of spending (16.4 percent of spending) for "gastroenterology signs and symptoms 1," indicating that this disease category likely represents a large amount of preventive treatment. By contrast, "malignant neoplasm of the rectum or anus" saw a decline in prevalence. Similar to cardiology services, there seems to be shift in prevalence from later-stage severe illnesses to preventive care. This growth in prevalence of preventive treatment may be attributable to the new screening guidelines instituted by the Committee of the American College of Gastroenterology (ACG) in 2000. ${ }^{29}$ Note that, although prevalence declined for rectal cancer, expenditures per capita rose significantly over the sample period. Our decompo-

\footnotetext{
${ }^{29}$ The ACG recommends colonoscopy every 10 years, beginning at age 50, as the preferred strategy. This is in contrast to a menu of options strategy endorsed by the American Cancer Society.
} 
sition shows that this was mainly attributable to the large growth in the cost of treatment (the $M C E$ index grew by approximately 50 percent). As we discuss in Section 4.3.4, many other types of cancer also reported large growth in treatment costs over the sample period.

\subsubsection{Gynecology}

Table 6. Gynecology

\begin{tabular}{|c|c|c|c|c|c|c|c|c|c|}
\hline & \multirow{2}{*}{\begin{tabular}{|cc}
2003 \\
Expenditure \\
per Capita
\end{tabular}} & \multirow{2}{*}{$\begin{array}{c}2007 \\
\text { Expenditure } \\
\text { per Capita } \\
\end{array}$} & \multicolumn{7}{|c|}{2007 Indexes } \\
\hline & & & $\mathrm{ECl}$ & DEM & $\mathrm{DECl}$ & PREV & MCE & SPI & SUI \\
\hline Malignant neoplasm of breast 1 & $\$ 26$ & $\$ 41$ & 1.60 & 1.10 & 1.50 & 1.07 & 1.40 & 1.27 & 1.10 \\
\hline Non-malignant neoplasm of female genital tract 3 & $\$ 19$ & $\$ 21$ & 1.09 & 0.99 & 1.09 & 1.02 & 1.07 & 1.16 & 0.92 \\
\hline Malignant neoplasm of breast 2 & $\$ 17$ & $\$ 25$ & 1.52 & 1.03 & 1.49 & 1.10 & 1.36 & 1.28 & 1.06 \\
\hline Conditions associated with menstruation 1 & $\$ 15$ & $\$ 14$ & 0.99 & 1.01 & 0.99 & 0.87 & 1.14 & 1.13 & 1.03 \\
\hline Non-malignant neoplasm of female genital tract 1 & $\$ 12$ & $\$ 15$ & 1.18 & 0.99 & 1.19 & 0.94 & 1.26 & 1.19 & 1.06 \\
\hline Non-malignant neoplasm of breast 1 & $\$ 11$ & $\$ 11$ & 1.03 & 1.01 & 1.02 & 0.85 & 1.20 & 1.18 & 1.02 \\
\hline Endometriosis 1 & $\$ 9$ & $\$ 8$ & 0.89 & 0.98 & 0.90 & 0.82 & 1.10 & 1.14 & 0.97 \\
\hline Conditions associated with menstruation 2 & $\$ 9$ & $\$ 13$ & 1.43 & 0.99 & 1.43 & 1.11 & 1.29 & 1.21 & 1.07 \\
\hline Other diseases of female genital tract 1 & $\$ 9$ & $\$ 9$ & 1.08 & 1.03 & 1.05 & 1.04 & 1.01 & 1.17 & 0.86 \\
\hline Malignant neoplasm of breast 3 & $\$ 8$ & $\$ 10$ & 1.33 & 1.02 & 1.31 & 1.07 & 1.23 & 1.26 & 0.98 \\
\hline
\end{tabular}

As shown in Table 2, gynecology was the fourth largest diagnostic category in 2003 but the fifth largest in 2007, falling behind endocrinology. This was attributable to the slightly lower-than-average growth in ECI (23 percent) for this diagnostic category. Table 6 reports the ten largest gynecological diseases in terms of expenditures per capita. These ten diseases made up about three-quarters of 2003 gynecological spending. The results show that the lower-than-average spending was mainly attributable to "nonmalignant neoplasm of the genital tract 3 and 1," "non-malignant neoplasm of the breast 1," and "conditions associated with menstruation 1." Expenditures for these diseases all grew less than 10 percent over the 2003 to 2007 sample period. Our decomposition shows that cost of treatment $(M C E)$ growth was about average for these diseases, however, they had low growth in prevalence and had negligible growth due to demographic factors. By contrast, the highest spending gynecological disease, breast cancer, had large growth 
in the cost of treatment - 40 percent growth in $M C E$ for severity 1 and 36 percent growth in $M C E$ for severity 2.

\subsubsection{Neoplasms}

Table 7. Neoplasms

\begin{tabular}{|c|c|c|c|c|c|c|c|c|c|c|}
\hline & & \multirow{2}{*}{\multicolumn{2}{|c|}{\begin{tabular}{||cc||}
2003 & 2007 \\
Expenditure & Expenditure \\
per Capita & per Capita
\end{tabular}}} & \multicolumn{7}{|c|}{2007 Indexes } \\
\hline & & & & $\mathrm{ECl}$ & DEM & $\mathrm{DECl}$ & PREV & $\mathrm{MCE}$ & SPI & SUI \\
\hline \multirow{2}{*}{ Neoplasm of breast } & Malignant & $\$ 50$ & $\$ 77$ & 1.53 & 1.06 & 1.47 & 1.07 & 1.37 & 1.27 & 1.33 \\
\hline & Non-Malignant & $\$ 11$ & $\$ 12$ & 1.04 & 1.01 & 1.03 & 0.85 & 1.21 & 1.18 & 1.03 \\
\hline \multirow{2}{*}{ Neoplasm of pulmonary system } & Malignant & $\$ 16$ & $\$ 21$ & 1.27 & 1.09 & 1.17 & 0.95 & 1.23 & 1.28 & 1.40 \\
\hline & Non-Malignant & $\$ 1$ & $\$ 1$ & 1.12 & 1.03 & 1.09 & 1.04 & 1.05 & 0.97 & 1.08 \\
\hline \multirow{2}{*}{ Neoplasm of rectum or anus } & Malignant & $\$ 13$ & $\$ 21$ & 1.55 & 1.09 & 1.46 & 0.97 & 1.51 & 1.45 & 0.99 \\
\hline & Non-Malignant & $\$ 2$ & $\$ 3$ & 1.73 & 1.09 & 1.64 & 1.52 & 1.08 & 1.06 & 1.04 \\
\hline \multirow{2}{*}{ Neoplasm of prostate } & Malignant & $\$ 13$ & $\$ 20$ & 1.55 & 1.15 & 1.40 & 1.09 & 1.29 & 1.17 & 1.07 \\
\hline & Non-Malignant & $\$ 4$ & $\$ 6$ & 1.56 & 1.13 & 1.43 & 1.06 & 1.35 & 1.15 & 1.19 \\
\hline \multirow{2}{*}{ Neoplasm of skin, major } & Malignant & $\$ 10$ & \$14 & 1.35 & 1.08 & 1.28 & 1.08 & 1.18 & 1.11 & 1.04 \\
\hline & Non-Malignant & $\$ 15$ & $\$ 19$ & 1.27 & 1.03 & 1.25 & 1.13 & 1.10 & 1.11 & 1.00 \\
\hline \multirow{3}{*}{ All neoplasms } & Malignant & $\$ 162$ & $\$ 240$ & 1.48 & 1.08 & 1.40 & 1.08 & 1.30 & 1.25 & 1.05 \\
\hline & Non-Malignant & $\$ 107$ & $\$ 133$ & 1.24 & 1.03 & 1.21 & 1.11 & 1.11 & 1.15 & 0.98 \\
\hline & All other diseases & $\$ 2,247$ & $\$ 2,856$ & 1.27 & 1.03 & 1.24 & 1.10 & 1.13 & 1.15 & 0.99 \\
\hline
\end{tabular}

To more comprehensively assess expenditure growth for cancer treatment, we group neoplasm conditions in Table 7. Specifically, we display the five most expensive neoplasm conditions (in terms of expenditures per capita), both malignant neoplasms and nonmalignant neoplasms separately. For ease of display, we aggregated severity types into one disease category (e.g., neoplasm of breast 1, 2, and 3 were aggregated into "neoplasm of breast"). Note that neoplasms are not a MPC, rather we pull neoplasms from a across different MPCs to compare them for Table 7. At the bottom of the table we also report aggregated indexes of all malignant and non-malignant neoplasms, along with aggregated indexes of all conditions but neoplasms. ${ }^{30}$

\footnotetext{
${ }^{30}$ For instance, the aggregated $E C I$ for non-malignant neoplasms was calculated as $E C I_{N o n, t}=$ $\sum_{d \in N o n} \omega_{d} \cdot E C I_{d, t}$ where $\omega_{d}=\frac{C_{d, 0}}{\sum_{d \in N o n} C_{d, 0}}$ and Non are the set of non-malignant diseases.
} 
The first result to note is that "non-malignant neoplasms" look very similar to "all other diseases." Specifically, the $M C E$ for non-malignant neoplasm treatment grew by 11 percent over the sample period, slightly below the 13 percent growth in all other diseases. By contrast, the cost of treatment for malignant neoplasms grew much more rapidly, with an $M C E$ growth of 30 percent. Faster growth for malignant neoplasms is attributable to both service prices, which grew by 25 percent, and service utilization, which grew by 5 percent. A plausible reason for this discrepancy between malignant neoplasms and the rest of the sample is the distinct and likely innovative technologies that are used to treat malignant neoplasms. Note that in our framework, when a procedure is first introduced into the market (i.e., an innovation), it will show up as an increase in utilization if this new procedure is measured to have a large quantity of $R V U \mathrm{~s}$. Furthermore, its price may subsequently increase as the new procedure diffuses and demand rises.

\section{Conclusion}

This paper presents a descriptive picture of the various sources of health-care expenditure growth. Our decomposition shows that growth in both service prices and prevalence of treated disease are responsible for the large increase in nominal medicalcare expenditure growth. Other factors, such as changes in the demographics of the population or changes in service utilization, have a limited impact on expenditures.

Perhaps equally important to the descriptive findings of this study are the avenues for future research that it reveals. For instance, our analysis shows that there has been tremendous growth in preventive service expenditures. Future research may decipher whether these preventive services ultimately lead to lower expenditures in the future, better health outcomes, or both. Second, although utilization has been declining for some diseases due to a shift from inpatient to outpatient services, some areas such as the treatment for malignant neoplasms have seen a growth in both service utilization and service prices. We hypothesize that this growth in the cost of treatment is attributable to the large degree of innovation for cancer treatment. However, a more comprehensive study specific to cancer treatment will likely lead to a better understanding of this cost of treatment growth. Third, future research may uncover if the shift in treated prevalence 
toward diseases that lead to ischemic heart failure (e.g., hypertension and hyperlipidemia) and away from ischemic failure is due to a worsening health status of the population or if it is attributable to better awareness of these types of conditions or more individuals with a condition seeking treatment. If the growth is attributable to an earlier awareness of a health condition, this may translate into lower expenditure growth or better health outcomes in the future.

\section{References}

[1] Aizcorbe, Ana and Nicole Nestoriak, (2011), "Changing Mix of Medical Care Services: Stylized Facts and Implications for Price Indexes", Journal of Health Economics, 30(3) pgs 568-574.

[2] Aizcrobe, Ana, Eli Liebman, Sarah Pack, David Cutler, Michael Chernew and Allison Rosen, (2012), "Measuring Health Care Costs of Individuals with EmployerSponsored Health Insurance in the U.S.: A Comparison of Survey and Claims Data", Statistical Journal of the International Association for Official Statistics, 28(1-2), pgs 43-51.

[3] Berndt, Ernst, David Cutler, Richard Frank, Zvi Griliches, Joseph Newhouse, and Jack Triplett, (2000), "Medical Care Prices and Output", Handbook of Health Economics, Chapter 3.

[4] Bundorf, Kate, Anne Royalty, and Laurence Baker, (2009), "Health Care Cost Growth Among the Privately Insured", Health Affairs, September/October.

[5] Chandra, Amitabh and Jonathan Skinner, (2012), "Technology Growth and Expenditure Growth in Health Care", Journal of Economic Literature, 50(3) pgs 645-680.

[6] Chernew, Michael and Joseph Newhouse, (2012), "Health Care Spending Growth", Handbook of Health Economics, Chapter 1 pgs 1-43.

[7] Cutler, David M., Mark McClellan, Joseph P. Newhouse, and Dahlia Remler. "Are Medical Prices Declining? Evidence from Heart Attack Treatments." Quarterly Journal of Economics 113 (1998) pgs 991-1024. 
[8] Dunn, Abe, Eli Liebman, Sarah Pack, and Adam Shapiro, (2012), "Medical Care Price Indexes for Patients with Employer-Provided Insurance: NationallyRepresentative Estimates from MarketScan Data", Health Services Research, Forthcoming.

[9] Dunn, Abe, Eli Liebman, Lindsey Rittmueller, and Adam Shapiro, (2014), "Defining Disease Episodes and the Effects on the Components of Expenditure Growth", Bureau of Economic Analysis, Working Paper.

[10] Dunn, Abe, Eli Liebman, and Adam Shapiro, (2014a), "Developing a Framework for Decomposing Medical-Care Expenditure Growth: Exploring Issues of Representativeness", Chapter 17 in Dale Jorgenson, Steven Landefeld, and Paul Schreyer, eds., Measuring Economic Sustainability and Progress, NBER Book Series Studies in Income and Wealth, Forthcoming.

[11] Dunn, Abe, Eli Liebman, and Adam Shapiro, (2014b), "Implications of Utilization Shifts on Medical-Care Price Measurement", Health Economics, Forthcoming.

[12] Dunn, Abe, Adam Shapiro, and Eli Liebman, (2014), "Geographic Variation in Commercial Medical-Care Expenditures: A Framework for Decomposing Price and Utilization", Journal of Health Economics, 32(6), pgs 1153-1165.

[13] Roehrig, Charles and David Rousseau, (2011), "The Growth in Cost Per Case Explains Far More of US Health Spending Increases Than Rising Disease Prevalence", Health Affairs, 30(9) pgs 1657-1663.

[14] Rosen, Allison, Eli Liebman, Ana Aizcorbe, and David Cutler, (2012), "Comparing Commercial Systems for Characterizing Episodes of Care", Bureau of Economic Analysis, Working Paper.

[15] Starr, Martha, Laura Dominiak, and Ana Aizcorbe, (2014), "Decomposing Growth in Spending Finds Annual Cost of Treatment Contributed Most to Spending Growth, 1980-2006", Health Affairs, 33(5) pgs 1657-1663.

[16] Thorpe, Kenneth, Curtis Florence, and Peter Joski, (2004), "Which Medical Conditions Account for the Rise in Health Care Spending?", Health Affairs, August - Web Exclusive. 
[17] Zuvekas, Samuel. and Gary Olin, (2009), "Accuracy of Medicare Expenditures in the Medical Expenditure Panel Survey", Inquiry, 46 pgs 92-108. 